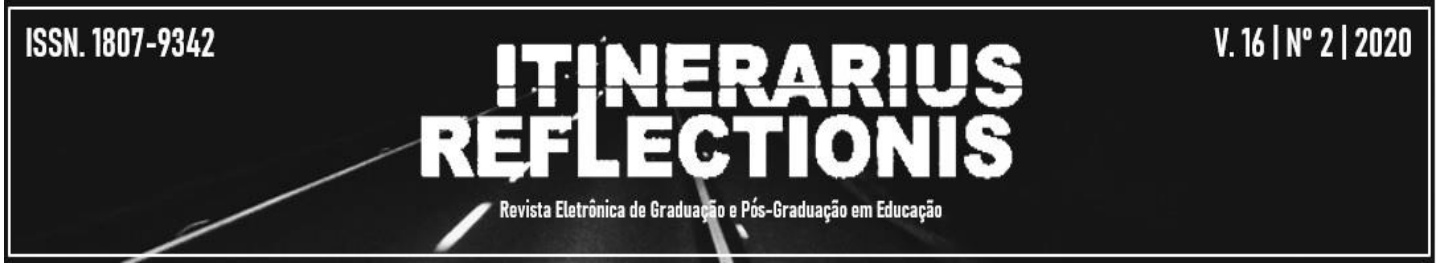

\title{
A educação no brasil na onda das transformações dos séculos xix e xx: reflexões sobre a modernidade e a modernização
}

\author{
Gabriela Marques de Sousa ${ }^{1}$ \\ Juliano Guerra Rocha ${ }^{2}$
}

Resumo: Desde a Independência do Brasil, diferentes iniciativas tentaram instituir um Estado moderno, entretanto um cenário social e político marcado, sobretudo, pelos ideais da colonização, da mistura entre privado e público, do sistema escravocrata e do patriarcalismo fez com que ideias racionais não se difundissem pelas províncias do país. Em 1889, a República foi instalada em meio a crises e disputas, com um governo baseado nos modelos estadunidense e positivista. A partir de então, a ciência e educação foram propagandeadas como elementos para tirar o país do atraso. À luz disso, partindo de uma reflexão sobre as concepções de modernidade e modernização na Europa nos séculos XIX e XX, este trabalho analisa ambas as ideias nas transformações políticoeducacionais no Brasil, entre o período imperial e republicano. No decorrer do artigo, também é evidenciada a relação histórica entre educação e civilização, para compreensão dos modos como a escola brasileira foi concebida.

Palavras-chave: Brasil; Educação; Modernidade; Modernização.

\begin{abstract}
Since the Independence of Brazil, different initiatives have attempted to establish a modern state; however, a social and political scenario marked, above all, by the ideals of colonization, the mixture between private and public, the slave system and patriarchalism, has made rational ideas the provinces of the country. In 1889, the Republic was installed in the midst of crises and disputes, being composed by a government based on the American and positivist models. From then on, science and education were propagandized as elements to take the country out of backwardness. In light of this, starting from a reflection on the conceptions of modernity and modernization in Europe in the XIX and XX centuries, this work analyzes both ideas in the political-educational transformations in Brazil, between the imperial and republican period. In the course of the article, the historical relationship between education and civilization is also evidenced, in order to understand the ways in which the Brazilian school was conceived.
\end{abstract}

Key-words: Brazil; Education; Modernit; Modernization.

\section{Considerações iniciais}

\footnotetext{
1 Doutoranda e Mestre em Educação pela Universidade Federal de Uberlândia. E-mail: gabrielamar.sousa@gmail.com.

${ }_{2}^{2}$ Doutor em Educação pela Universidade Federal de Uberlândia. Mestre em Educação pela Universidade Estadual de Campinas. Professor da Secretaria de Estado da Educação de Goiás e da Secretaria Municipal da Educação de Itumbiara/GO. E-mail: professorjulianoguerra@gmail.com.
} 


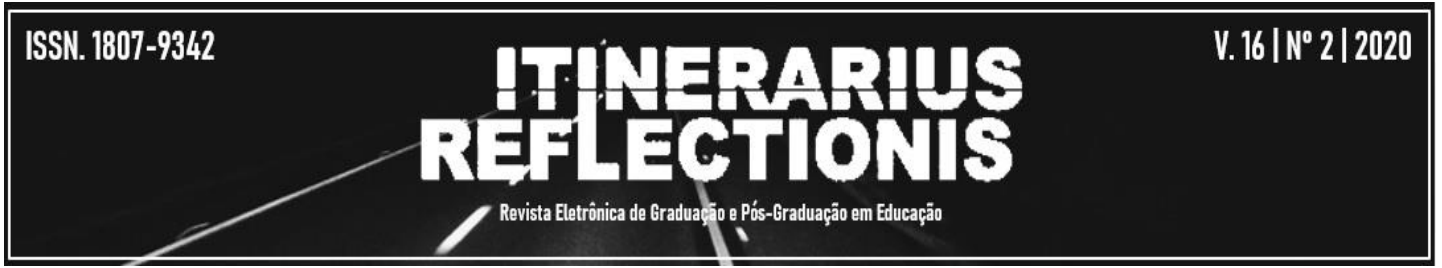

O conceito de modernidade clássica está diretamente associado à formação de um novo pensamento social e político surgido na Europa a partir do século XVI. Sob a luz das novas ideias, o homem passou a ser concebido como um ser dotado de razão, capaz de interferir na sua realidade.

Segundo Touraine (1994), a modernidade caracteriza-se como ciclo de acontecimentos, sendo concebido a partir da difusão dos produtos da atividade racional, científica, tecnológica e administrativa. Do mesmo modo, esse conceito está associado a dois aspectos: racionalização e secularização. O primeiro, ligado à organização da vida pessoal e coletiva que, por consequência, nos leva ao segundo ponto, sob a égide da separação do primeiro com a ideia de "fins dos tempos".

Nessa perspectiva, a modernidade rompeu com o divino ou sagrado, em benefício de um sistema em que prevalecesse a racionalização das operações. A consolidação desse pensamento ocorreu a partir do século XVIII, em que as mudanças ocorridas foram cruciais para os processos que haviam sido iniciados com a Era Moderna $^{3}$. Essas transformações levaram à crise o sistema político-social vigente, marcado por duas revoluções: Industrial e Francesa. Para Hobsbawn (2009), essa "dupla revolução" foi assinalada por uma torrente de mobilização social, tendo como pano de fundo a cultural vitória da ideologia secular sobre a religiosa, em que o vocabulário e as instituições políticas e sociais foram secularizados.

Se a revolução britânica contribuiu para gerar o modelo urbano, educacional e trabalhista, a revolução francesa propiciou o modelo político e ideológico para o processo de modernização (HOBSBAWN, 1996). Com efeito, as duas revoluções introduziram na sociedade novos modelos de vivência, isto é, ambas proporcionaram uma série de "revoluções" no campo tecnológico - com o florescimento da indústria têxtil inglesa do algodão e a indústria metalúrgica; no campo agrícola - com o uso de máquinas, inserção de novas técnicas, cultivos e alteração no regime de exploração da terra; no campo demográfico e de urbanização - com a criação de mercados internos e externos que fomentaram a demanda ou pressão por novas tecnologias e/ou inovações na organização do processo produtivo.

${ }^{3}$ De modo geral, a Era Moderna (ou Idade Moderna) inicia-se na Europa com a queda do Império Bizantino, em 1453, estendendo-se até a Revolução Francesa, em 1789. Esse período ficou marcado pelas diversas transformações ocorridas na sociedade nos aspectos culturais, sociais, políticos e geográfico. Marcou o início do pensamento moderno, tendo como principais representantes René Descartes (15961650) e John Locke (1632-1704). 


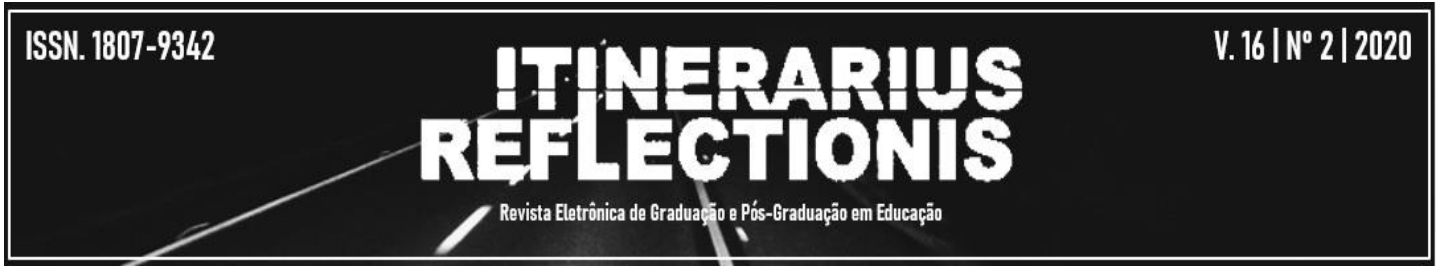

Por meio da instituição desses modelos e da reestruturação da relação entre o

Estado e a sociedade civil, no século seguinte consagraram-se as ideias de modernidade, que se disseminaram para diversos países, constituindo um novo paradigma. Nesse sentido, a educação também foi atingida, sendo compreendida como o caminho que possibilitaria a abertura do indivíduo "[...] ao conhecimento racional e à participação em uma sociedade em que a ação da razão se organiza, [sendo] a escola [...] um lugar de ruptura com o meio de origem e de abertura ao progresso [...]" (TOURAINE, 1994, p. 20).

Por consequência, pouco a pouco, o poder sobre a educação passou a ser do Estado, com a monopolização dos saberes e, ao mesmo tempo, a responsabilidade pela escolarização da população. Essas iniciativas substituíram a chamada pedagogização das relações sociais e a ação das famílias na educação dos filhos. Desse modo, no século XIX, não bastava apenas "tornar gestos e ações previsíveis, foi preciso indicar o caminho da produção da previsibilidade [...] para toda a sociedade" por meio da educação (VEIGA, 2002, p. 99). De igual maneira, a educação deslocou-se cada vez mais para a esfera da vida pública, deixando de ser um direito ou ação, majoritariamente, da família. Dessa forma, a organização e sistematização da educação foi assumida como um dos princípios norteadores para a construção de um Estado eficiente e eficaz, isto é, o Estado moderno, em que o discurso da universalização dos saberes e a escolarização prevalecia para o triunfo da ideia de civilização. Para Veiga,

Portanto, a perspectiva do Estado em incluir os pobres na escolarização para completar o processo civilizatório pressupôs a homogeneização das relações sociais que, ao mesmo tempo, somente se estabeleceram como homogênicas por pressuporem uma diferenciação. Concretamente, nesse sentido, a escola estrutura-se como prática social com base no dispositivo escolarização; é produtora e reprodutora de formas sociais, da socialização, expressa na difusão da cultura escrita, do saber científico, e na produção dos talentos e da individualização (VEIGA, 2002, p. 100, grifos da autora).

No caso do Brasil, a ideia de Estado moderno, baseado no processo de civilização da sociedade, é inconcebível. Isto porque, segundo Veiga (2002), a modernidade não aconteceu aos moldes europeus, já que, naquele continente, fora construída a partir de um longo período histórico bem demarcado. Para a autora, apesar de o Estado e as elites intelectuais e políticas brasileiras assumirem o termo, esse foi 


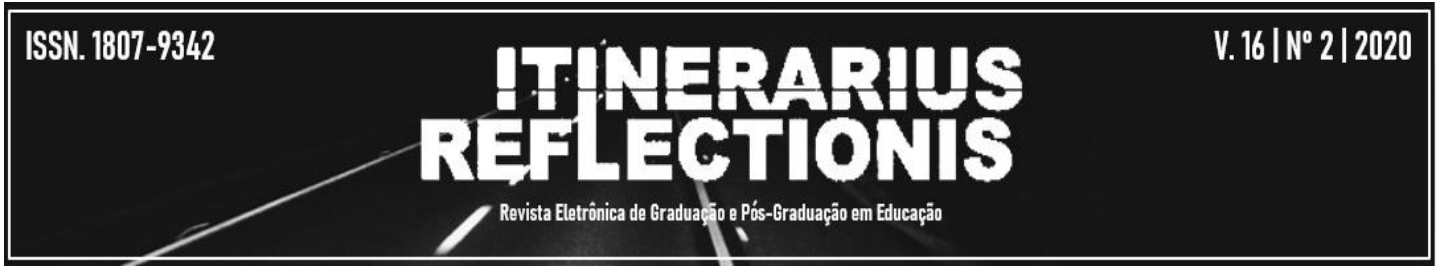

tomado apenas como referência para a produção de uma autoimagem, servindo de parâmetro de comparação com outras sociedades.

Além disso, a independência do país não causou transformações estruturais nos poderes já estabelecidos, uma vez que foram mantidas as mesmas relações sociais e políticas entre as elites do período anterior. Diferentemente dos Estados europeus, em que o público e o privado tinham linhas bem delineadas, o "Estado brasileiro possibilitou a produção de uma cultura de poder público indistinta do privado, favorecendo o desencadeamento de redes de clientelismo, cujos laços de interdependência eram muito fortes" (VEIGA, 2002, p. 101). Essa tendência prevaleceu nos anos posteriores, perpassando os primeiros anos da República.

Este texto, portanto, tem como objetivo fazer apontamentos sobre o processo de modernidade e modernização da educação, evidenciando de que maneira essas ideias foram concebidas e incorporadas pelo Estado, a partir do século XIX. Ademais, buscaremos, brevemente, compreender a realidade do Brasil frente às novas propostas modernizadoras para a educação.

\section{Entre a modernidade e a modernização da educação: o público e o privado do final do século XIX ao início do XX}

Se a noção mais recorrente sobre a modernidade está vinculada a uma ruptura entre o novo e velho, entre o passado e o presente, buscando demarcar o princípio de uma nova relação com o mundo tradicional frente ao mundo moderno, distanciando-se daquilo que estava posto até então e aproximando-se de uma ideia técnico-científica, ao atravessarmos para o século XIX o paradigma modernizador avança, atribuindo novos sentidos para o ser, substituindo-o pela ordem coletiva e estatal.

Diante disso, o sujeito deixa de existir para se submeter às vontades da sociedade e o Estado torna-se o centralizador das ações, aproximando-se cada vez mais das ideias cientificistas. Ao mesmo tempo, esse último toma para si a função de conduzir o homem à modernidade e, por consequência, à civilidade e ao progresso, entendendo-se como único capaz de balizar os desejos de todos. Segundo Touraine, entre os séculos XIX e XX, além da separação entre Igreja e Estado,

[...] é preciso acrescentar, mais importante e mais radical ainda, a separação entre sociedade e Estado, o que torna a afastar a ideia de sociedade como um conjunto, sistema ou corpo social, e sublinhar a 


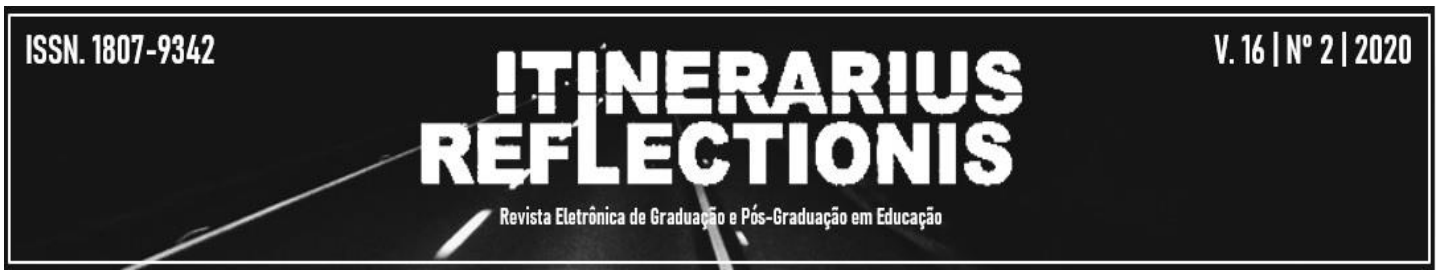

oposição entre a ideia de sociedade e a realidade da vida social, aberta, multável e pluralista (TOURAINE, 1994, p. 103, grifos do autor).

Assim, o sistema de mercado, a indústria, a ciência e a nação tornaram-se os pilares dos discursos da modernidade ao longo do século XIX até o século XX, constituindo-se como projetos do Estado cientificista, fundamentado por meio do paradigma biológico. Logo, “a ideia de modernidade é substituída pela ação modernizadora [que] liberta o indivíduo e a sociedade até então prisioneiros das leis impessoais da razão depois de terem sido da lei divina" (TOURAINE, 1994, p. 107).

Nesse sentido, a questão da modernidade e da modernização durante o século XIX legitima o discurso da ciência, da busca pela verdade, do êxito econômico e da eficácia técnica, que ressoam no desenrolar do século XX e reverberam, paulatinamente, nas relações entre a vida pública e a vida privada, redefinindo suas linhas. Dessa maneira,

\begin{abstract}
A mais forte concepção ocidental da modernidade, a que teve efeitos mais profundos, afirmou principalmente que a racionalização impunha a destruição dos laços sociais, dos sentimentos, dos costumes e das crenças chamadas tradicionais, e que o agente da modernização não era uma categoria ou uma classe social particular, mas a própria razão e a necessidade histórica que prepara seu triunfo. Assim, a racionalização, componente indispensável da modernidade, se torna além disso um mecanismo espontâneo e necessário de modernização (TOURAINE, 1994, p. 18-19).
\end{abstract}

À medida que avançam essas ideias e se estabelece um novo paradigma relacionado ao moderno, os espaços sociais são reorientados. O trabalho doméstico, que até então era configurado no interior das casas, adquire aspectos da modernidade, isto é, "[...] os locais de trabalho já não são mais os da vida doméstica", passando a ser da vida pública.

[...] Essa diferenciação dos locais vem acompanhada por uma diferenciação das normas: o universo doméstico se liberta das regras anteriormente ligadas ao trabalho que ali se realizava, ao passo que o mundo do trabalho passa a ser regido, não mais por normas de ordem privada, e sim por contratos coletivos (PROST, 2009, p. 23).

O rearranjo da vida pública associado à concepção de coletividade atribui à família novos significados, deslocando-a das suas funções públicas para as funções privadas. E, mais do que isso, esse movimento acarreta na privatização das famílias, o 


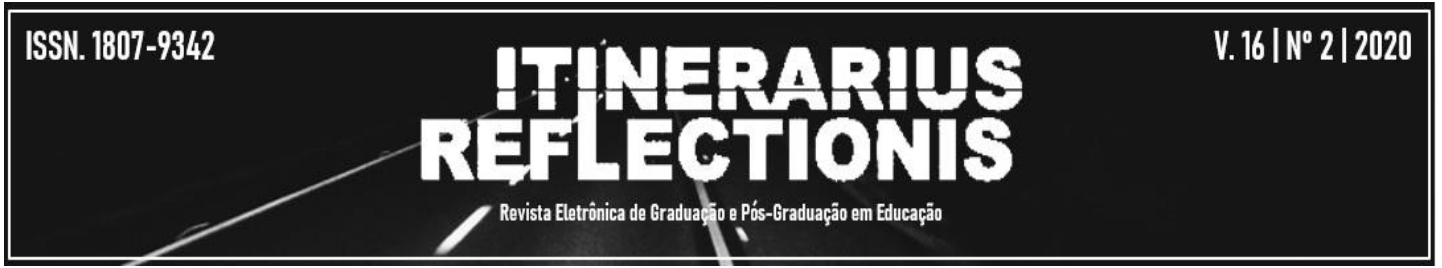

que significa dizer que é, também, desinstitucionalização familiar. De acordo com Prost (2009, p. 61), “[...] uma parte das tarefas antes confiadas a ela foi gradualmente assumida por instâncias coletivas; com a socialização de certas funções", sobrando apenas os assuntos que tangessem a realização da vida privada.

Do final do século XIX para o século XX, a educação, que era gerida no interior das casas, passa a ser administrada pelo poder público. Isto significa dizer que a nação toma o lugar do indivíduo, repercutindo nas tradições socioculturais ligadas à família. Para a ação modernizadora do Estado, seria necessária uma aliança com a racionalidade instrumental, "[...] ao passo que os ataques contra a técnica estão associados à orientação antimoderna e integralista de cada um dos elementos da modernidade" (TOURAINE, 1994, p. 112).

Esses elementos - ou como define Touraine (1994, p.143): "esses atores da modernização" - configuram-se como a nação, a empresa e o consumo. Todos fundamentados no discurso sobre o desenvolvimento da técnica, pois, à medida que a modernidade entrava em crise, abria-se cada vez mais espaço para a modernização. $\mathrm{Na}$ lógica, essa última provocaria a separação dos universos culturais da modernidade, porém o que garante a associação desse conjunto dentro da modernização é a razão instrumental, ou seja, a técnica. Assim,

\begin{abstract}
[...] a nação pode afirmar sua independência e sua diferença; ela também deve gerar administração, organizar a produção e o consumo, equipar um exército. Tudo isso supõe o recurso à técnica, mesmo quando se trata de um regime teocrático ou integralista. A empresa é um agente de mudança econômica antes de ser uma organização, mas ela é também um conjunto de técnicas de produção e comunicação [...] No âmbito do consumo, o cálculo racional está sempre presente, ao mesmo tempo que as escolhas manifestam uma personalidade ou orientações culturais (TOURAINE, 1994, p. 155).
\end{abstract}

Diante disso, é em nome da utilidade social, da substituição do egoísmo pelo altruísmo, de formar cidadãos que cumpram seus deveres e que, ao mesmo tempo, exerçam seus papéis de acordo com as regras para a criação de uma sociedade racional e equilibrada que o apelo às técnicas irá garantir a primazia do Estado frente à educação.

Porém, não era qualquer educação, mas, sim, uma educação caracterizada pela concepção de socialização do indivíduo e ascensão da razão, de maneira que a criança devesse ser disciplinada e estimulada por castigos ou prêmios, com a finalidade de 


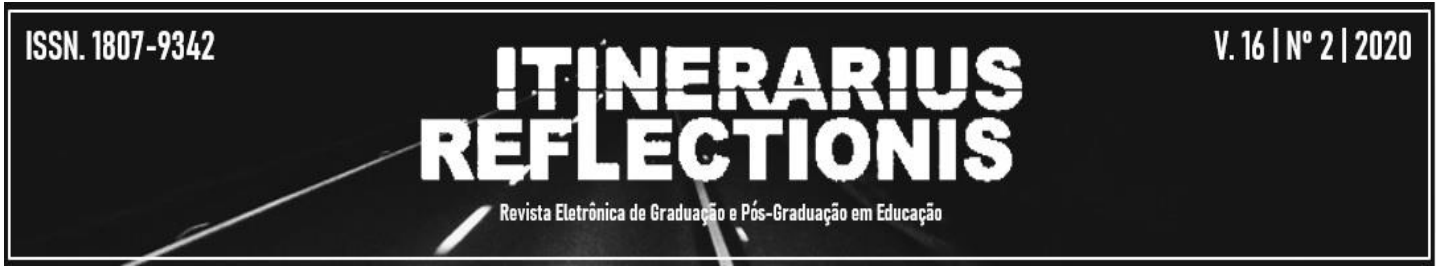

dominar seus desejos individuais e aprender as regras da vida em sociedade e os procedimentos do pensamento racional, sendo

[...] o objetivo dessa educação cheia de coação [...] dar ao indivíduo a capacidade de resistir às dificuldades materiais, mas sobretudo intelectuais e morais que ele encontrará durante a sua vida. Ele deverá ser capaz de ser senhor de si, de dar provas de coragem e sacrifício. A educação é a aprendizagem do dever, e não é por acaso que a palavra dever designa também a tarefa imposta pelo professor ao aluno, e disciplina designa ao mesmo tempo uma obrigação, um instrumento de punição e um domínio de conhecimento (TOURAINE, 1994, p. 270).

Se na modernidade a educação foi concebida a partir do princípio da racionalização, devendo libertar o indivíduo de uma visão estreita e irracional, com o objetivo de integrá-lo à sociedade movida pela ação da razão, devendo ser útil para a realização das atividades, com o avanço do ideário de modernização a defesa a favor do desenvolvimento da nação torna-se cada vez mais intensa, atribuindo ao Estado nacional o papel de agente principal para a geração de uma cultura, difundida pelas escolas. Segundo Touraine (1994), é através da cultura nacional que se constituirá a consciência coletiva, sendo o Estado responsável pela difusão, generalização, imposição de uma cultura que será legitimada por intermédio das escolas, da administração pública e das forças armadas. Para o autor,

[...] a nação não é a figura principal da política, ela é o ator principal da modernização, o que significa que ela é o ator não moderno que cria a modernidade sobre a qual ela procurará preservar o controle, ao mesmo tempo que aceitará perdê-lo em parte, em benefício de uma produção e de um consumo internacionalizado (TOURAINE, 1994, p. 146 , grifos do autor).

A compreensão de que a nação é o agente principal do processo de modernização contribuiu para que ela fosse responsável não apenas pela mudança no que tange à finalidade e à organização da educação, mas também no que se refere ao sistema político e econômico das sociedades europeias.

Nesse sentido, ao tratarmos de modernidade e modernização na Europa entre os séculos XIX e XX, estamos evidenciando a construção do conceito de civilização, o qual abarca concepções da construção de uma sociedade pautada no conhecimento científico, no domínio das técnicas, e de um mercado capitalista desenvolvido. Esse 


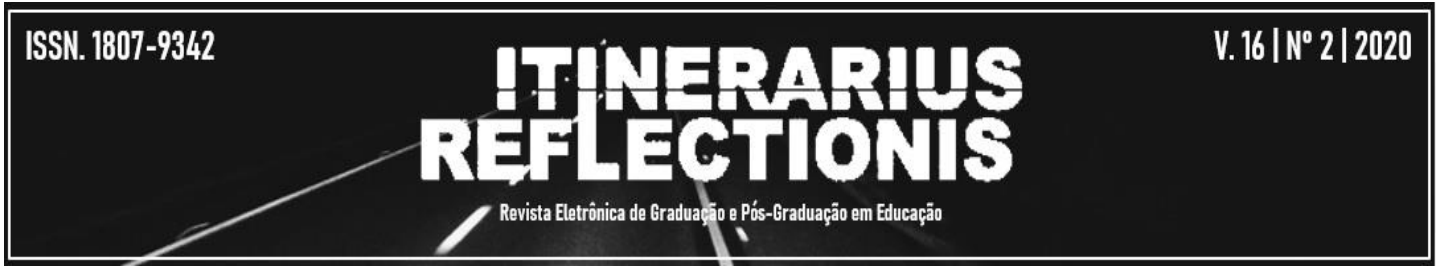

cenário só foi possível de se consolidar diante do triunfo da razão, do desenvolvimento da ciência e do avanço da indústria.

Portanto, ao trazer esses conceitos para a realidade brasileira no mesmo período, deve-se ter em mente que o contexto social e político era muito diferente da realidade europeia. Dessa forma, por mais que as tendências modernizadoras chegassem ao Brasil, não eram aplicadas e/ou recebidas da mesma maneira.

No próximo tópico, apresentaremos, a partir das discussões de Veiga (2002) e Herschmann e Pereira (1994), de que modo foram implantadas, no final do século XIX, as ideias de modernidade e modernização no Brasil e as transformações causadas na sociedade.

\section{$O$ antigo e o moderno no Brasil: a (des)continuidade do império na primeira república}

A modernidade foi compreendida como capaz de mudar a ordem político-social, causando transformações significativas na cultura e nas tradições do mundo ocidental. A principal transformação do ideário moderno foi a cisão entre Estado e Igreja, concebendo o primeiro como o fruto da razão, devendo distanciar-se das paixões e dos limites que a doutrina cristã impunha ao indivíduo.

Deus dava lugar ao homem, fundamentado na ciência e nas ideias racionalistas. Por consequência, essa racionalização das operações e a separação entre objetivo e subjetivo influenciaram a organização e sistematização da educação. Cabia então à escola formar o homem que fosse útil e funcional, baseado em uma moral social. Para o Estado moderno, só esse tipo de sujeito era benéfico para a sociedade, fazendo parte dessa concepção a união do "[...] bom cidadão, bom trabalhador, bom pai ou boa filha" (TOURAINE, 1994, p. 102). Apenas esses aspectos alçavam a sociedade moderna à posição de civilizada.

Segundo Veiga (2002), o processo civilizador só pode ser concebido a partir da escolarização do século XIX, pois se origina da extensão do autocontrole ao conjunto das relações sociais e a extensão do controle da violência sobre as crianças, reverberando na vida privadas das famílias. Igualmente,

[...] o modelo de civilização produzido previa a reprodução das formas de comportamento presentes no interior de uma configuração social aristocrático-burguesa, para toda a população, de forma que 


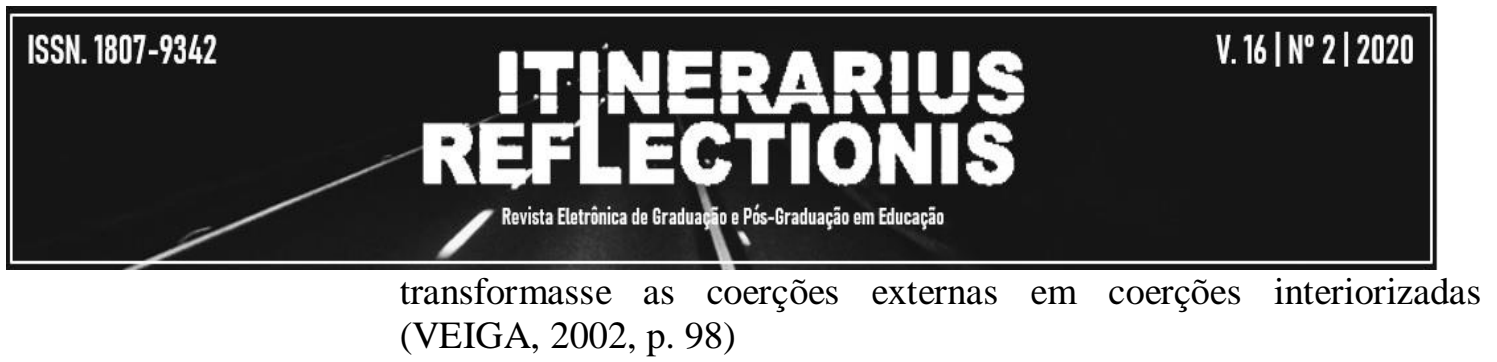

Nessa perspectiva, o Estado se legitimou como o detentor dos saberes e, vagarosamente, foi assumindo a educação e aumentando suas ações no que tange aos processos de escolarização. Essa transformação foi ainda mais profunda na medida em que, além da socialização dos aprendizados, a escolarização também proporcionaria o aprendizado da sociedade. Se antes a família era o núcleo da educação, considerada a base social, a transferência do trabalho para fora da família associada à ação do Estado frente à promoção da educação

[...] faz com que a família transfira para a escola o aprendizado da vida em sociedade. A escola recebe a incumbência de ensinar os filhos a respeitar as obrigações do tempo e do espaço, as regras que permitem viver em comum e encontrar a relação justa e adequada com os demais. E essa socialização não diz respeito apenas aos anos da adolescência: toda a escolarização ocorre para ela (PROST, 2009, p. 82).

É nesse sentido que Veiga argumenta ter sido a difusão da escolarização essencial para os "processos de alteração da sociabilidade em curso, ao longo do século XIX e no início do XX” (VEIGA, 2002, p. 99). Contudo, esse cenário só se torna visível ao constatarmos o desenvolvimento da modernidade e do processo de modernização na Europa.

No caso do Brasil, desde a Independência, houve diversas iniciativas para constituição de um Estado moderno, embora o contexto social e político vigente, nesse período, não favorecesse o fortalecimento de ideias racionais, baseadas na técnica e na ciência. Dessa forma, as tentativas de introduzir no país as ideias de modernidade europeia fizeram parte do discurso sobre a educação e instrução pública, sendo sua referência uma constante no desenvolvimento de políticas educacionais e implantação de escolas. Entretanto, na prática, o investimento no campo educacional ainda era muito incipiente, devido à descentralização política e aos aspectos sociais e culturais da sociedade brasileira daquele período.

Com efeito, a defesa da racionalização da educação, do final do século XIX até meados do século XX, correspondia, também, às expectativas de alguns intelectuais e políticos brasileiros. Isso porque 


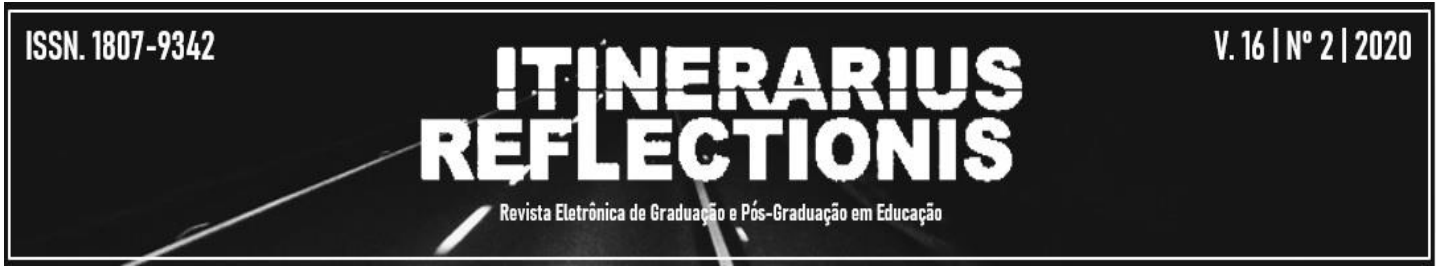

[...] o período que vai do último quartel do século XIX ao começo dos anos 20, no Brasil, é de profundas e rápidas transformações sociais e políticas. A abolição da escravatura em 1888 e a proclamação da República em 1889 haviam aberto caminho para a construção de uma nova sociedade capaz de absorver as novas ideias [...] Saía-se do escravismo e ingressava-se no processo de uma sociedade de tipo capitalista urbano-industrial. Entre 1889 a 1930, vive-se o que ficou conhecido como a República Velha, marcada pela presença das oligarquias regionais e pela fraqueza de um poder central. É a crise desta estrutura política, econômica, social e cultural que marcará a vida brasileira durante a década de 1920, culminando na Revolução de 30. A partir de então começava-se a implementar não apenas uma nova ordem republicana, mas, sobretudo, um novo modelo de Brasil, o modelo de Brasil moderno (HERSCHMANN; PEREIRA, 1994, p. grifos dos autores).

É na efervescência dessas discussões associadas às ideias de progresso e civilização que a escola passa a constituir-se como lócus da formação do futuro cidadão e, por consequência, responsabiliza-se pela constituição da sociedade moderna. Esse movimento já começa no fim do Império intensificando-se com a progressiva ideia de fundar a República. Porém, diante da realidade brasileira nesse período, como é concebida a ideia desse cidadão? Ou, melhor dizendo, tratando-se da transição do período imperial para a instauração da República, a educação poderia ser considerada o meio que formaria o cidadão brasileiro, pautado na ideia de modernidade?

Esse questionamento se faz necessário, tendo em vista que o discurso sobre a educação formar o cidadão destoa da realidade brasileira no final do século XIX e início do XX. Dessa forma, Veiga (2002) argumenta que, diferentemente das sociedades europeias, em que a formação dos Estados nacionais se assentou na herança das relações feudais, o Estado brasileiro

[...] estruturou-se baseado em laços de interdependência entre os membros da aristocracia e das elites econômicas, o que possibilitou inclusive o rompimento com a metrópole; ou seja, um acordo entre aristocracia e proprietários de escravos (VEIGA, 2002, p. 101).

Essa tendência permaneceu mesmo com a proclamação da República, em 1889. A discussão sobre qual modelo republicano seria adotado provocou caos na sociedade brasileira. Segundo Herschmann e Pereira, “[...] o ponto crucial do debate era a relação entre público e privado e/ou indivíduo e comunidade" (1994, p. 25), o que resultou na 


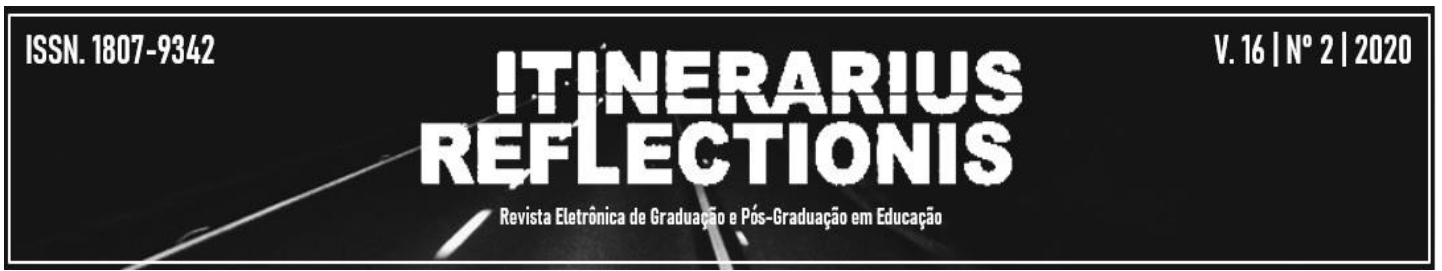

escolha por um sistema de governo baseado na mistura entre o modelo estadunidense e o positivista.

Foi pela adoção desse modelo que a ciência se tornou parte integrante das discussões sobre a retirada o país do atraso, sendo considerada elemento imprescindível da mudança. Segundo Faoro, a modificação “[...]se daria, pensava-se, com o retorno do espírito de Pombal, reerguendo a tocha da ciência" (FAORO, 1992, p. 11). Assim, argumenta o autor que

[...] as correntes de pensamento diziam que havia um mundo renovado, que era preciso rearticular ao País cadaveroso. O veículo para renovação era a ciência [...] a ciência como salvação, retomandose, nas elites que a promoviam, os elos viáveis das reformas pombalinas. Todas as ideias postas em circulação acentuavam que a "ciência era o valor mais alto da cultura humana, capaz de resolver todos os problemas" [...] O desenvolvimento do País se daria, portanto, pela via da ciência, cultivada nas academias militares, na Escola Politécnica e nas faculdades de Medicina. Comte recupera Pombal, num Iluminismo, como o do déspota português, tolhido e politicamente condicionado (FAORO, 1992, p. 11, grifos do autor).

Os modelos e valores europeus de sociedade serviram de parâmetro comparativo sobre a ideia de civilização no contexto brasileiro naquele período, “[...]foram aglutinados em formulações filosóficas e científicas que procuravam ter junto à sociedade um efeito moral e normatizador" (HERSCHMANN; PEREIRA, 1994, p. 26). "Vencer o atraso colonial" - ecoava em todos os cantos do país. O cenário do início da República configurou-se como a busca por uma ciência aplicada, isto é, a ciência da técnica, passando ela a ser considerada essencial para o destino da nação.

Para esse fim, os médicos, os engenheiros e os educadores foram tidos como os sujeitos aptos para a condução da sociedade brasileira ao progresso, uma vez que eram diretamente ligados à racionalidade científica. Todavia, esse grupo de pessoas que tomou para si a "ciência como missão" - sendo esse um dos princípios do positivismo não se atentou à realidade brasileira. Ou seja, a modernização foi via prussiana, segundo Faoro (1992), e não estava de acordo com o contexto social da época. Isso significa dizer que

[...] a sociedade brasileira, mesmo nos centros urbanos, não se modificou ou aceitou as mudanças pacificamente e muito menos rapidamente. Esse Estado que se propôs orquestrar esses indivíduos, articulando-se a um saber técnico-científico, tinha diante de si uma 


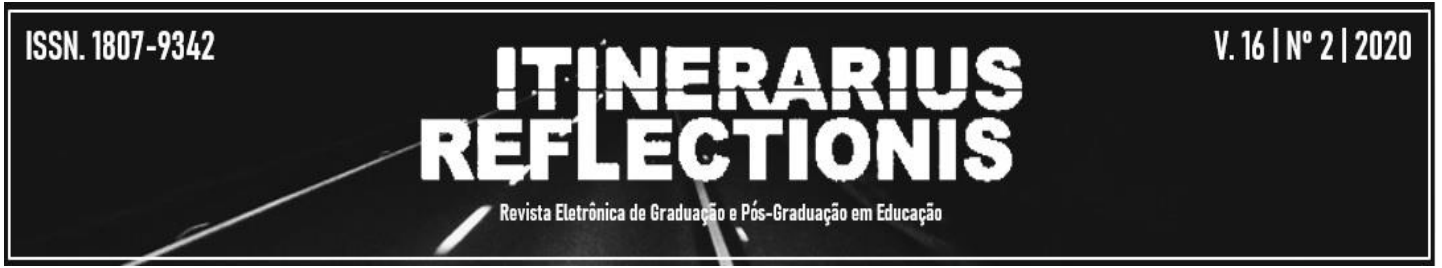

sociedade eminentemente patriarcal e que ainda se comportava como tal [...] A sociedade brasileira, evidentemente, não respondeu homogeneamente a essas "reformas", uma vez que a maioria da população ainda organizava suas vidas de acordo com os valores tradicionais, clientelistas, bem longe do modelo de estrutura social oferecido pelo Estado (HERSCHMANN; PEREIRA, 1994, p. 26-27).

O que houve entre o Império e a República foi uma constante crítica ao sistema social vigente, cerceado pela cultura e tradição do período anterior a 1889. Por mais que houvesse tentativas de modernização da ordem posta, as relações sociais mantinham-se as mesmas. $\mathrm{O}$ descompasso entre o projeto modernizador brasileiro e a necessidade da nação tornou-se evidente quando aquele não causou ruptura com o passado nem a mudança tão almejada.

Isso porque, para o triunfo da modernidade, não basta tirar Deus do centro da sociedade e colocar a ciência em seu lugar, como princípio norteador dos avanços políticos, sociais e econômicos. Era preciso ir além. A atividade intelectual devendo ser protegida das propagandas políticas e das crenças religiosas, as leis deveriam ter caráter impessoal e protegidas das ameaças do nepotismo, do clientelismo e da corrupção. Os interesses públicos deveriam ser distintos dos interesses privados, para que os primeiros não fossem utilizados a favor dos segundos (TOURAINE, 1994).

De acordo com Veiga (2002), o processo de monopolização dos saberes pelo Estado brasileiro, ao contrário de em outros países, se deu por meio do processo de monopolização da força física. Diante disso, não houve, por parte dos dirigentes, uma procura por "completar um projeto de civilização já em curso",

[...] mas de estabelecer as civilidades, e, principalmente, legitimar e dar visibilidade a uma nova configuração de poder em construção. Isso se manifestou principalmente na produção de cargos públicos e de uma rede de funcionalismo, inserindo novas relações de poder na rotina das populações (VEIGA, 2002, p. 101).

Se o princípio da escola moderna era o rompimento com os costumes da família e ao mesmo tempo uma aprendizagem sobre a vida em sociedade com o objetivo de constituir um cidadão útil para o progresso social e a civilização, a escola e a escolarização brasileira, entre o final do século XIX e início do XX, não colaborou para a modernização, pois reforçava a presença do indivíduo à frente da sociedade. Por consequência, a escolarização permaneceu como privilégio das elites, acentuando a 


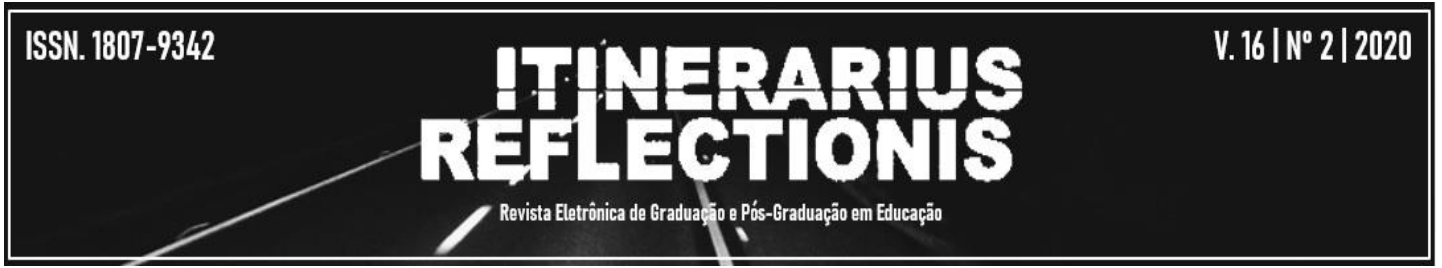

presença de uma educação com o viés da Igreja e da família, o que impossibilitava o triunfo da ideia da ciência e da técnica dentro das escolas.

\section{Considerações finais}

A possibilidade de se constituir uma nova ordem e se distanciar de um mundo considerado atrasado norteou de forma mais intensiva os rumos da sociedade europeia. O triunfo da razão e da ciência fez com que o homem se tornasse personagem principal do seu destino. O céu e a terra haviam se distanciado e a Igreja deixou de ser majoritariamente detentora dos saberes e decisória nas ações dos Estados.

Porém, a modernidade clássica vivia em uma bolha - assim como as ideias Iluministas - protegida de tudo que perturbasse a razão e a ordem natural das coisas (TOURAINE, 1994). A concepção de um governo que baseasse suas escolhas na racionalidade era falsa, pois a realidade social não escondia os conflitos e os embates pelo poder. Assim, a modernização surgiu como alternativa para tornar a sociedade moderna, encontrando refúgio junto ao desenvolvimento da indústria e das ideias de liberdade, igualdade e fraternidade.

A nação então tornou-se o ator principal do processo de modernização e o Estado nacional o representante e o balizador dos desejos de todos. A coletividade e o progresso da sociedade tomaram o lugar do indivíduo e da família. Civilizar era a palavra de ordem; tornar o homem útil e apto para o trabalho era um dos deveres do Estado moderno.

Mas isso só seria possível diante do quadro social, político, econômico e cultural da Europa do século XIX, baseado no progresso da ciência e da técnica. No Brasil, no mesmo período, a realidade era muito diferente. As heranças coloniais, a mistura entre o público e privado, o sistema escravocrata e o patriarcalismo não possibilitavam a implementação de uma educação que visasse a civilizar a sociedade e moldar o homem, no sentido de constituir uma civilização brasileira.

Esse cenário permaneceu mesmo com a instauração da República e as iniciativas de políticos e intelectuais. Como demonstram as análises de Veiga (2002), Faoro (1992) e Herschmann e Pereira (1994), o Estado republicano brasileiro, nos seus primeiros anos, não conseguiu modificar as relações estabelecidas desde o Império, o 


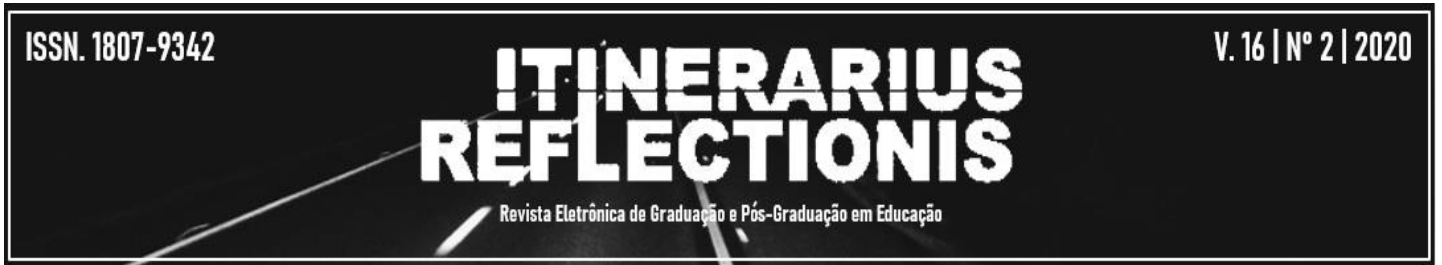

que demonstra que, por mais que a educação, a ciência, a técnica e o desenvolvimento da indústria fizessem

parte do projeto de modernização da sociedade e do discurso político, não causaram as transformações necessárias para constituir uma nação civilizada e progressista.

Dessa forma, o que fica claro é uma divergência entre a proposta e a realidade brasileira. O projeto modernizador da sociedade não encontrou terreno pronto para se fundar, logo, esse discurso modernizante traduzia apenas os anseios da elite política e intelectual do Brasil, que via a ciência e o Estado como os precursores de tão desejada modernização.

\section{Referências}

FAORO, Raymundo. A questão nacional: modernização. Estudos avançados, São Paulo, v. 6, n. 14, p. 7-22, 1992. Disponível em: <http://www.revistas.usp.br/eav/ article/view/9563>. Acesso em: 02 dez. 2017.

HERSCHMANN, Micael M.; PEREIRA, Carlos Alberto Messeder. O imaginário moderno no Brasil. In: HERSCHMANN, Micael M.; PEREIRA, Carlos Alberto Messeder (Orgs.). A invenção do Brasil Moderno: medicina, educação e engenharia nos anos 20-30. Rio de Janeiro: Rocco. 1994.

HOBSBAWN, Eric. Ecos da Marselhesa: Dois Séculos Reveem a Revolução Francesa. Tradução: Maria Célia Paoli. São Paulo: Companhia das Letras. 1996.

Era das Revoluções, 1789 - 1848. Tradução: Marcos Penchel e Maria L. Teixeira. 25a edição. São Paulo: Paz e Terra. 2009.

PROST, Antoine. Fronteiras e espaços do privado: introdução; o trabalho. In: PROST, Antoine; VINCENT, Gérard (Orgs.). História da Vida Privada, 5: da Primeira Guerra a nossos dias. Tradução: Denide Bottman. São Paulo: Companhia das Letras. 1992a. p. 13-59.

A família e o indivíduo. In: PROST, Antoine; VINCENT, Gérard (Orgs.). História da Vida Privada, 5: da Primeira Guerra a nossos dias. Tradução: Denide Bottman. São Paulo: Companhia das Letras. 1992b. p. 61-113.

TOURAINE, Alain. Crítica da Modernidade, Tradução: Elia Ferreira Edel. $5^{\circ}$ ed. Petrópolis, RJ: Vozes. 1994.

VEIGA, Cynthia Greive. A escolarização como projeto de civilização. Revista Brasileira de Educação, n. 21, p. 90-103, set./dez. de 2002. Disponível em: <http://www.scielo.br/pdf/rbedu/n21/n21a07>. Acesso em: 22 nov. 2017. 


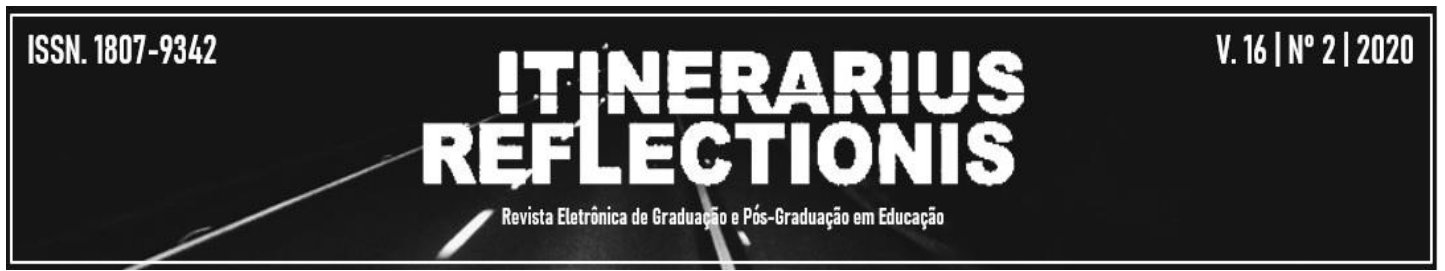

